\title{
Experimental characterization of dynamic deformation behaviour for SCM440 steel at high strain rates
}

\author{
Keunho Lee ${ }^{1 *}$, Yerim Lee ${ }^{1}$, Sanghyun Woo ${ }^{1,2}$, Changsoo Lee ${ }^{1}$, and Leeju Park $^{1,2}$ \\ ${ }^{1}$ The 4th Research and Development Institute, Agency for Defense Development, 34186 Daejeon, Republic of Korea \\ ${ }^{2}$ Weapon Systems Engineering, Korea University of Science and Technology, 34113 Daejeon, Republic of Korea
}

\begin{abstract}
The dynamic deformation behaviours of SCM 440 steel were characterized at the strain rates from $10^{-3} \mathrm{~s}^{-1}$ to $10^{6} \mathrm{~s}^{-1}$. The uniaxial tensile tests at different temperature of $25{ }^{\circ} \mathrm{C}, 350{ }^{\circ} \mathrm{C}$, and $700{ }^{\circ} \mathrm{C}$ were performed by a hydraulic universal testing machine equipped with a heating stage, and the compressive tests were conducted by using a spilt Hopkinson pressure bar (SHPB) at room temperature. Material coefficients of the Johnson-Cook constitutive model considering temperature effects were obtained based on the stressstrain relations from the experimental tests. In addition, Taylor impact tests on the SCM 440 steel were carried out to evaluate the accuracy of the determined material coefficients and characterize the dynamic behavior at the ultra-high strain rates and high temperature, by comparison with numerical simulations.
\end{abstract}

\section{Introduction}

The dynamic behaviour of materials at high strain rates ranging from $10^{2} \mathrm{~s}^{-1}$ to $10^{6} \mathrm{~s}^{-1}$ is intimately associated in several defense applications, such as blast effects, ballistics impacts, and crashworthiness. The demand for accurate analysis and understanding of the dynamic material behaviour has been growing to design and guarantee effective structures, which can endure high dynamic loads. Hence, much research has been conducted for characterizing the material properties and hardening behaviours under the high strain rates [1-5].

Since the hardening characteristics are remarkably changed by the extent of the temperature and strain rate, accurate experimental techniques are necessary to acquire the mechanical properties under static and dynamic loads. For the ultra-high strain rates higher than $10^{4} \mathrm{~s}^{-1}$ where stress-strain curves cannot be obtained by the experiments, it is indispensable to conduct numerical modelling and simulation with dynamic hardening models, which describe stressstrain relationship at various strain rates and different temperature. There are the well-known dynamic hardening models proposed by many researchers, including the Johnson-Cook model [6].

In this research, the quasi-static and dynamic deformation behaviours of SCM440 steel, which can be applied to the various parts of high explosive warheads such as shaped charge (SC) and explosively formed penetrator (EFP), were characterized at the strain rates from $10^{-3} \mathrm{~s}^{-1}$ to $10^{6} \mathrm{~s}^{-1}$. The uniaxial tensile tests at different temperature of $25{ }^{\circ} \mathrm{C}, 350{ }^{\circ} \mathrm{C}$, and 700 ${ }^{\circ} \mathrm{C}$ were performed by a hydraulic universal testing machine equipped with a heating stage, and the compressive tests were conducted by using a spilt Hopkinson pressure bar (SHPB) at room temperature. For precise characterization on hardening behaviour at the high strain rates, the true strain rate and temperature rise during the plastic deformation due to adiabatic heating effects were considered. The material coefficients of the Johnson-Cook constitutive model considering temperature effects were obtained based on the stress-strain relations from the experimental tests. In addition, Taylor impact tests on the SCM440 steel were carried out to evaluate the accuracy of the determined material coefficients and characterize the dynamic behaviour at the ultra-high strain rates and high temperature, by comparison with numerical simulations.

\section{Experiments and numerical simulation}

Commercial SCM440 steel has been selected as a test material, which is one of the low carbon high strength steels. The chemical compositions of the SCM440 steel are shown in Table 1. The SCM440 steel was fabricated in the form of a hot-rolled bar with $110 \mathrm{~mm}$ diameter.

Table 1. Chemical composition of the SCM440 steel (wt.\%).

\begin{tabular}{|c|c|c|c|c|}
\hline $\mathrm{C}$ & $\mathrm{Si}$ & $\mathrm{Mn}$ & $\mathrm{Cr}$ & $\mathrm{Mo}$ \\
\hline 0.39 & 0.22 & 0.69 & 0.95 & 0.15 \\
\hline
\end{tabular}

The specimen for microstructural observation was prepared by mechanical grinding followed by 
electropolishing and etching with a $10 \%$ perchloric acid solution and a $4 \%$ nital solution, respectively. The microstructure was observed on the plane normal to extrusion direction by means of optical microscopy.

Quasi-static uniaxial tensile tests were performed to obtain the stress-strain response with respect to the temperature up to the strain rate of $10^{0} \mathrm{~s}^{-1}$ by MTS 810 equipped with a heating stage. The static tensile test specimens for room temperature have the gauge length of $30 \mathrm{~mm}$ with the diameter $5 \mathrm{~mm}$ based on ASTM E8M. The displacement of the specimen was obtained by ARAMIS Digital Image Correlation (DIC) system (GOM, Germany), which can measure relative displacements between characteristic points on the serial digital images according to time. For preparing of the tensile specimen applied to DIC system, a black speckle pattern was formed using spray paint to create a high contrast with the white surface coating. The displacement measurement was taken from this surface pattern [7].

The tensile test specimens for high temperature $\left(350{ }^{\circ} \mathrm{C}\right.$ and $700{ }^{\circ} \mathrm{C}$ ) have the gauge length of $100 \mathrm{~mm}$ with the diameter $6.3 \mathrm{~mm}$. In order to confirm the temperature profile of the specimen during the deformation process, k-type thermocouple wire was spot-welded at the centre of the gage section, and the temperature was continuously monitored [8].

The compressive SHPB tests were carried out at strain rates of $1.9 \times 10^{3} \mathrm{~s}^{-1}$. The form of the SHPB specimen is a disk with the length of $3.3 \mathrm{~mm}$, and the diameter of $8.65 \mathrm{~mm}$. The wave signal of the SHPB tests was detected from the strain gauge which were attached in the transmitted bar. At least three specimen for the quasi-static and dynamic tests were tested at the same condition of strain rate and temperature.

Taylor impact test was conducted with a single stage gas gun. The Taylor impact test is a general experimental technique, which impacts a cylindrical projectile specimen on an anvil with a high velocity. In order to launch the projectile specimen with a target velocity, the impact velocity should be calibrated with consideration of the launching pressure, the specimen weight, and the vacuum condition [5]. In addition, a specially designed sabot was utilized to grab the projectile specimen in the gas gun and to control the alignment of the projectile flight. The length and diameter of the Taylor impact test specimen are $50 \mathrm{~mm}$ and $10 \mathrm{~mm}$, respectively. The shape change of the projectile during the test was captured with in-situ observation utilizing a high speed camera. The numerical simulations of the Taylor test were performed with commercial finite element software, AUTODYN 2D axisymmetric elements with the Johnson-Cook model.

\section{Results and Discussion}

\subsection{Initial microstructure}

Figure 1 shows the optical micrograph of the initial SCM440 steel. The initial specimen is mostly composed of acicular ferrite and bainite phases, which can be distinguished by the brightness of the image since the dark bainite has a higher Carbon content than the bright ferrite. Morphological characteristics of the constitutional phases indicate that the SCM440 steel might be annealed at a lower transformation temperature and quenched to room temperature.

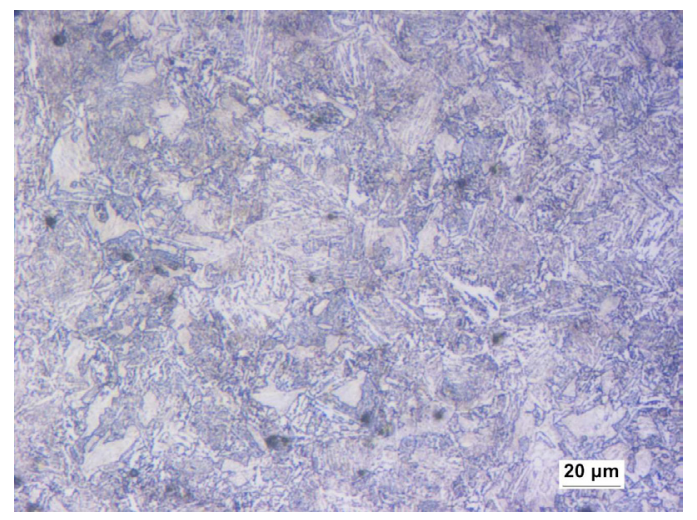

Fig. 1. Optical micrograph of initial SCM440 steel.

\subsection{Quasi-static and dynamic deformation behaviours}

Engineering stress-strain curves with respect to strain rate at room temperature are shown in Fig. 2(a). As strain strain rate increases, both yield stress and flow stress increase especially in the strain rate of $1.9 \times 10^{3}$ $\mathrm{s}^{-1}$. The yield strength of $1.9 \times 10^{3} \mathrm{~s}^{-1}$ is $1240 \mathrm{MPa}$, which is quite higher than 533 and $546 \mathrm{MPa}$ for $10^{-3} \mathrm{~s}^{-1}$ and $10^{0} \mathrm{~s}^{-1}$, respectively. Magnified engineering stressstrain curves inserted in Fig. 2(a) clearly exhibit the yield point phenomena at the incipient plastic yielding in $10^{-3} \mathrm{~s}^{-1}$ and $10^{0} \mathrm{~s}^{-1}$. To acquire the material coefficients of the hardening model precisely, the engineering stress-strain data in the range of the yield point phenomena were excluded from the analysis.

The true stress-strain curves of all strain rate conditions were obtained from the engineering stressstrain curves using experimental data until the ultimate tensile strength. During the calculation process, the raw experimental data were smoothed with the adjacent adjacent-averaging method. As one of examples, Fig. 2(b) exhibits the raw experimental true stress-strain data along with the smoothened results at strain rates of $10^{-3} \mathrm{~s}^{-1}$.

Figure 3 shows the true plastic stress-strain curves at various conditions of the strain rate and temperature. It is noted that the flow stress of the SCM440 steel increases as the strain rate increases and the temperature decreases. These tendencies are regarded as the inherent characteristics of most metallic materials.

\subsection{Evaluation of dynamic hardening model}

The dynamic hardening models are important for representing the stress-strain relationship of the 
metallic materials at various strain rates and different temperature, considering the strain hardening, strain rate hardening, and thermal softening effect. Among the several suggested models, the Johnson-Cook model [6] is one of the well-known and widely used models describing the dynamic hardening characteristics as follows:

$$
\sigma=\left[A+B \varepsilon^{n}\right]\left[1+C \ln \frac{\dot{\varepsilon}}{\dot{\varepsilon}_{0}}\right]\left[1-\left(\frac{T-T_{r}}{T_{m}-T_{r}}\right)^{m}\right]
$$

where $\varepsilon$ is the equivalent plastic true strain, $\varepsilon / \varepsilon_{0}$ is the dimensionless plastic strain rate for $\mathcal{E}_{O}=1 \mathrm{~s}^{-1}$, and $T_{r}$ and $T_{m}$ are the reference temperature and the melting temperature of the material, respectively. The five coefficients are adopted as $A, B, n, C$, and $m$. The expression in the first term of brackets represents the stress as a function of strain for $\mathcal{E}_{O}=1 \mathrm{~s}^{-1}$ and $T=T_{r}$. The second and third terms of brackets represent strain rate hardening and thermal softening effects, respectively.
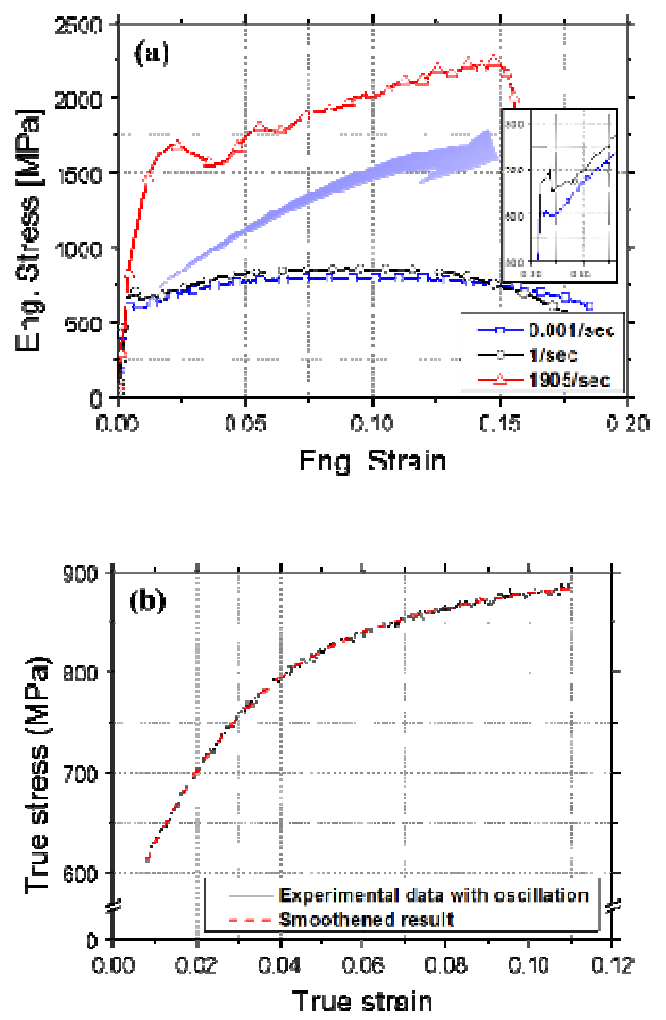

Fig. 2. (a) Engineering stress-strain curves at strain rates from $10^{-3}$ to $1.9 \times 10^{3} \mathrm{~s}^{-1}$. Magnified engineering stress-strain curves at strain rates of $10^{-3}$ and $1 \mathrm{~s}^{-1}$ indicating the yield point phenomena were inserted in (a). (b) The raw experimental data and the smoothened results at strain rates of $10^{-3} \mathrm{~s}^{-1}$.

To ensure the accuracy for obtaining the material coefficients, the true strain rate and the thermal softening effects were considered since both the strain rate and the temperature were changed during the tests especially in high strain rates. During the test, the gauge length of the specimen changed continuously and so did the strain rate. We assume that the strain rate reduces during the test as an exponential function when the initial strain rate is above $1 \mathrm{~s}^{-1}[9]$ :

$$
\dot{\varepsilon}_{\text {true }}=\left(\frac{V}{L_{0}}\right) \exp (-\varepsilon)
$$

where $V$ is the tensile speed and $L_{0}$ is the gauge length. The temperature of the specimen also changed during the test. In this study, it is assumed that $90 \%$ of the plastic work for deformation is converted to the heat energy in the initial strain rate conditions above $1 \mathrm{~s}^{-1}$.
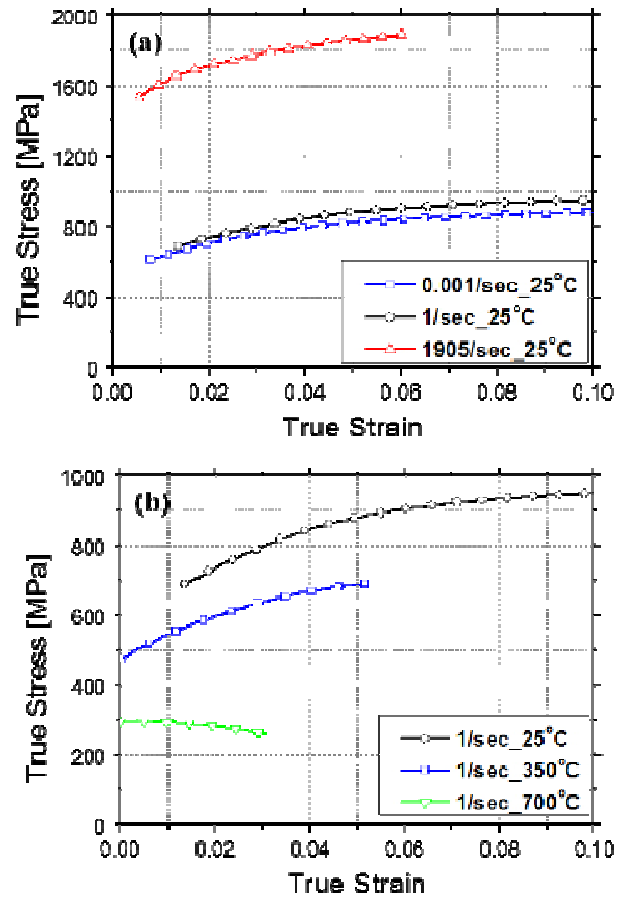

Fig. 3. (a) True plastic stress-strain curves at various strain rates at room temperature. (b) True plastic stress-strain curves at high temperature of 350 and $700{ }^{\circ} \mathrm{C}$ at strain rates of $1 \mathrm{~s}^{-1}$.

The temperature change due to the adiabatic heating can be expressed as follows:

$$
\Delta T=\frac{0.9}{\rho C} \int_{0}^{\varepsilon} \sigma(\varepsilon) d \varepsilon
$$

where $\rho$ is the density and $C$ is the specific heat coefficient. Material properties of the SCM440 steel are summarized in Table 2.

Table 2. Material properties of the SCM440 steel.

\begin{tabular}{|c|c|c|c|c|}
\hline $\begin{array}{c}\text { Specific } \\
\text { heat }\left(C_{p}\right) \\
{[\mathrm{J} /(\mathrm{KgK})]}\end{array}$ & $\begin{array}{c}\text { Shear } \\
\text { modulus } \\
(G) \\
{[\mathrm{GPa}]}\end{array}$ & $\begin{array}{c}\text { Poisson's } \\
\text { ratio }(v)\end{array}$ & $\begin{array}{c}\text { Density } \\
(\rho) \\
{\left[\mathrm{g} / \mathrm{cm}^{3}\right]}\end{array}$ & $\begin{array}{c}\text { Melting } \\
\text { temperat } \\
\text { ure }\left(T_{m}\right) \\
{\left[{ }^{\circ} \mathrm{C}\right]}\end{array}$ \\
\hline 473 & 80 & 0.3 & 7.85 & 1427 \\
\hline
\end{tabular}

Figure 4(a) shows yield stress change with respect to strain rates at the room temperature and fitted results of the Johnson-Cook model. The strain rate hardening is represented by the linear relationship for the Johnson-Cook model, and the strain rate constant 
which is the constant $\mathrm{C}$ in the Johnson-Cook model can be determined from the slope of the fitted line. Therefore, $A$ and $C$ are determined using yield stress change with respect to the strain rate change. And then, using all of the data points, $B, n$, and $m$ can be determined simultaneously by the least square method [9].

The fitted results of the Johnson-Cook model are shown in Fig. 4(b) with the true stress-strain curves at the various strain rates and temperature. The JohnsonCook model proposed model shows the good fitted results for the SCM440 steel. The material coefficients for the Johnson-Cook model of the SCM440 steel are summarized in Table 3.
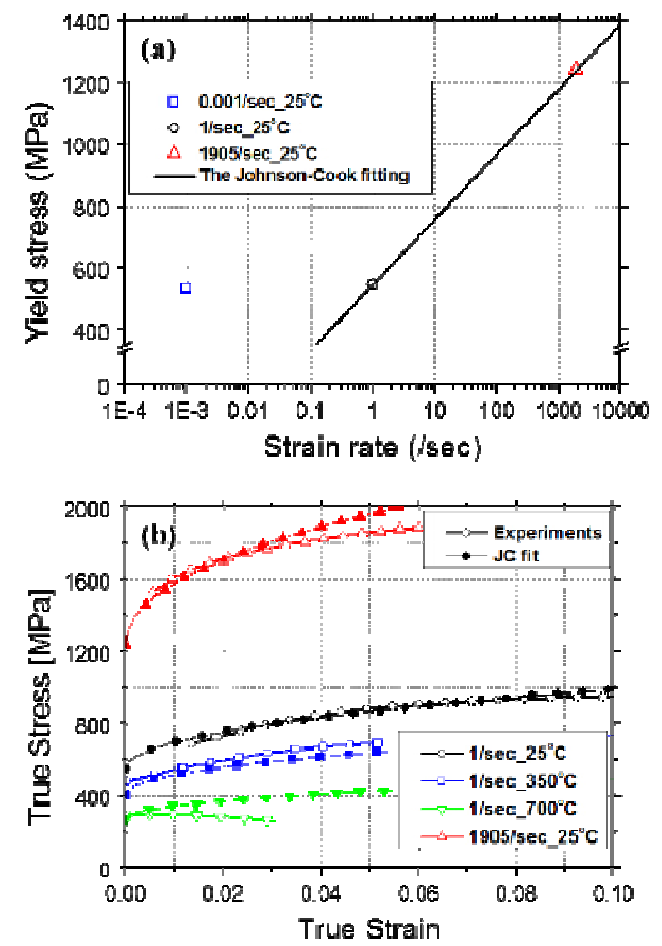

Fig. 4. (a) Yield stress change with respect to strain rates and fitted results of the Johnson-Cook model. (b) True stressstrain curves at the various strain rates and temperature, and the corresponding fitted results of the Johnson-Cook model.

Table 3. Material coefficients for the Johnson-Cook model.(ref. strain rate : $1 \mathrm{~s}^{-1}$, temperature $: 25^{\circ} \mathrm{C}$ ).

\begin{tabular}{|c|c|c|c|c|}
\hline $\mathrm{A}$ & $\mathrm{B}$ & $\mathrm{n}$ & $\mathrm{C}$ & $\mathrm{m}$ \\
\hline 546 & 1309 & 0.47 & 0.168 & 0.93 \\
\hline
\end{tabular}

\subsection{Taylor impact tests and comparison with numerical simulations}

Figure 5 shows the initial and final shape of the Taylor test projectile during the test. The impact velocity of the projectile was measured as $205 \mathrm{~m} / \mathrm{s}$. The diameter and the axial length in the deformed shapes are 14.25 $\mathrm{mm}$ and $43.92 \mathrm{~mm}$, respectively. Several numerical simulations were performed at different impact velocities of 150,205 , and $250 \mathrm{~m} / \mathrm{s}$, respectively. The average element size was carefully determined as 0.1 $\mathrm{mm}$, based on the computation time and accuracy of the numerical simulations.
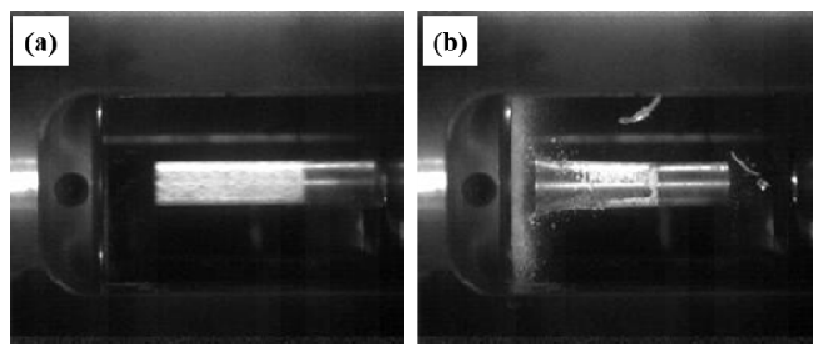

Fig. 5. (a) Initial and (b) Final deformed shapes of the Taylor test projectile at the impact velocity of $205 \mathrm{~m} / \mathrm{s}$.

The calculated shapes and temperature distributions at the different impact velocity are shown in Fig. 6. As the impact velocity increases, the axial length in the deformed shapes decreases and the diameter at the tip of the impact region increases. Though the Taylor test was carried out at the room temperature, the temperature of the projectile significantly increases due to the severe plastic deformation in a short time, which implies that the strain rate during the Taylor impact test must be quite high reached the ultra-high strain rates.


Fig. 6. Calculated shapes and temperature distributions at the impact velocity of: (a) $150 \mathrm{~m} / \mathrm{s}$; (b) $205 \mathrm{~m} / \mathrm{s}$; and (c) $250 \mathrm{~m} / \mathrm{s}$.

Figure 7 shows the maximum temperature and maximum strain rates during the Taylor impact simulations with respect to the impact velocity. The magnitude of the maximum strain rate in the projectile is higher than $10^{5} \mathrm{~s}^{-1}$ at the initial impact, and moreover it is higher than $10^{3} \mathrm{~s}^{-1}$ during the deformation until about $0.03 \mathrm{~ms}$. The results indicate that most region of the projectile is high strain rates over $10^{3} \mathrm{~s}^{-1}$.

The diameter and the axial length in the deformed shapes obtained from the numerical simulation at the impact velocity of $205 \mathrm{~m} / \mathrm{s}$ are $11.42 \mathrm{~mm}$ and 46.77 $\mathrm{mm}$, which is large deviation comparing with the experimental results. One of the main reasons for this large deviation might be that the dynamic hardening model obtained from the experimental static and dynamic properties could not accurately predict the hardening behaviours at the ultra-high strain rates due to inaccurate extrapolation. Therefore, as further study, it needs further modification of the material coefficients with a proper optimization procedure. 

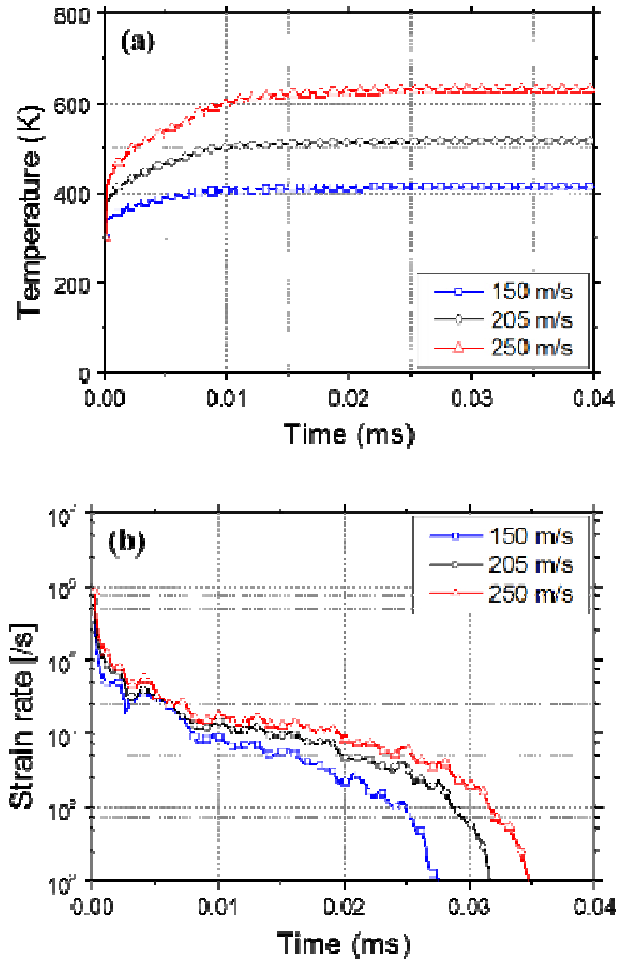

Fig. 7. (a) Maximum temperature and (b) maximum strain rates during the Taylor impact simulations with respect to the impact velocity.

\section{Conclusion}

In this study, the quasi-static and dynamic deformation behaviours of SCM440 steel were characterized at the strain rates from $10^{-3} \mathrm{~s}^{-1}$ to $10^{6} \mathrm{~s}^{-1}$. The initial microstructure of the SCM440 specimen is mostly composed of acicular ferrite and bainite phases. Both yield stress and flow stress from the uniaxial tensile and compressive tests increase as strain rate increases, and the yield point phenomena are clearly observed at the incipient plastic yielding during the static tensile tests. The material coefficients of the Johnson-Cook constitutive model were obtained from the experimental static and dynamic properties considering the true strain rate and temperature rise due to adiabatic heating. The numerical simulation of the Taylor impact tests were carried out and compared with the experimental results. The final deformed shapes of the Taylor tests show a large discrepancy between simulation and experimental results. The large deviation might originate from the inaccurate extrapolation of the dynamic hardening model, therefore further modification of the material coefficients will be conducted with a proper optimization procedure.

\section{References}

1. P.J. Maudlin, J.F. Bingert, J.W. House, S.R. Chen, Int. J. Plast. 15, 139 (1999)

2. J. Field, S. Walley, N Bourne, J. Huntley, J. de Phys. IV 04(C8), 3 (1994)

3. G.T. Gray III, P.J. Maudlin, L.M. Hull, Q.K. Zuo, S.-R. Chen, J. Fail. Anal. Prev. 5, 7 (2005)

4. I. Rohr, H. Nahme, K. Thoma, Int. J. Impact Eng. 31, 401 (2005)

5. M. Piao et al., Int. J. Impact Eng. 91, 142 (2016)

6. G.R. Johnson, W.H. Cook, Proceedings of the 7th International Symposium on Ballistics. 541 (1983)

7. H.-J. Jeong et al., Mater. Sci. \& Eng. A 684, 668 (2017)

8. J.Y. Choi et al., Mater. Sci. \& Eng. A 666, 280 (2016)

9. H. Huh et al., J. Mater. Proc. Tech. 214, 1326 (2014) 
